\title{
Study on radiation-induced radicals giving rise to stable EPR signal suitable for the detection of irradiation in L-sorbose-containing fruits
}

Grzegorz P. Guzik, Wactaw Stachowicz

\begin{abstract}
The stable and complex EPR signals produced by the action of ionizing radiation on crystalline L-sorbose $\left(\mathrm{C}_{6} \mathrm{H}_{12} \mathrm{O}_{6}\right)$ separated from rowan berries (Sorbus aucuparia) were studied. Isothermal heating of the samples at the temperature close to the melting point of L-sorbose $\left(140^{\circ} \mathrm{C}\right)$ results in the modification and simplification of the EPR signal involved. In the EPR signal of heated L-sorbose, the isotropic quartet was distinguished. In the differential spectrum obtained by subtraction of normalized spectra of unheated and heated L-sorbose, the isotropic doublet was identified in addition. The DFT fitting offers the probable assignment of the EPR signals to specific radical structures.
\end{abstract}

Key words: sorbose $\bullet$ crystallite $\bullet$ electron paramagnetic resonance $(\mathrm{EPR}) \bullet$ irradiation

\section{G. P. Guzik ${ }^{\bowtie}$, W. Stachowicz}

Institute of Nuclear Chemistry and Technology,

16 Dorodna Str., 03-195 Warsaw, Poland,

Tel.: +4822504 1122, +4822822 2603,

E-mail: iris12@op.pl

Received: 25 November 2015

Accepted: 31 May 2016

\section{Introduction}

Ionizing radiation is useful for the conservation and disinfestation of fresh and dried fruits. The treatment of fruits with gamma-rays or beams of accelerated electrons has been carefully tested and was recommended by FAO/WHO Codex Alimentarius Commission for the common use as an effective and safe preservation method [1]. It was found earlier that the ionizing radiation produces stable EPR signals in dried fruits, presumably derived from sugar radicals which are trapped in crystalline sugars [2, 3]. Radiation-induced EPR signals in dried fruits are relatively intense while their complexity (multiline spectrum) and broadness show conclusively that several radicals are involved. It is in contrast to the native EPR signals observed in non-irradiated dried fruits, which are weak single EPR lines. Radiation-induced EPR signal in dried fruit represents a broad, multiline spectrum in contrast to the native EPR signal observed in non-irradiated fruits, which is a weak single line or does not appear. Thus, the distinction in EPR between non-irradiated and irradiated fruit is very simple. The detection of a specific, complex EPR signal in fruits provides evidence for the radiation treatment of the latter $[4,5]$. The EPR detection of dried fruits treated with ionizing radiation has been tested in several interlaboratory exercises with 


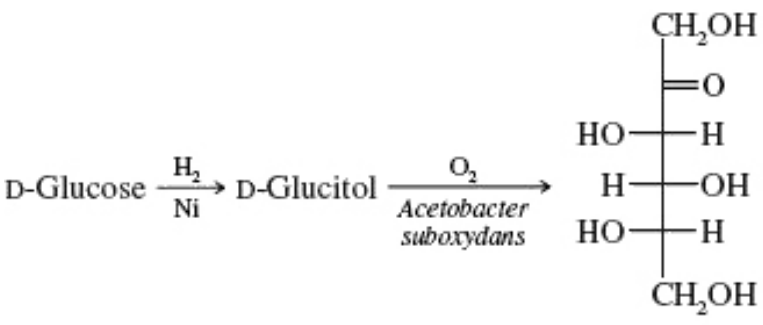

L-Sorbose

Fig. 1. Production of L-sorbose from D-glucose. D-Glucitol obtained from D-glucose by catalytic addition of $\mathrm{H}_{2}$ undergoes biotransformation by the action of Acetobacter suboxydans [12].

positive results [6]. Consequently, CEN Commission in Brussels legislated and issued the method of the detection of fruits containing crystalline sugar as European standards [7]. Presently, the standard is widely used for the control of irradiated fruits in many countries all over the world. The identity of radiation-induced EPR signal in fruits and radicals involved are not known and remain the subject of investigation. In our earlier studies, we focused our attention on the identification of radicals responsible for the dominating lines in the complex EPR spectra of irradiated fructose [8], glucose [9] and mannose [10], all separated from fruits. The original method developed by us for the examination of the EPR spectra recorded with samples of sugars unheated and heated to the temperatures close to their melting points was applied and proven as new way of possible radical identification in these systems [11].

In present work, we focused our attention on L-sorbose separated from rowan berries (Sorbus aucuparia). Rowan berries dried or powdered are used as the component of herbal preparations applied as antiphlogistic, laxative and/or diuretic agents. L-Sorbose appears in the peels of passion fruit (Passiflora edulis) cultivated in North and South America and in overgrowths [12]. L-Sorbose utilized in pharmaceutical industry is not separated from fruits but produced from glucose (Fig. 1). Commercial production of vitamin C (ascorbic acid) also begins with sorbose as a basic reagent.

L-Sorbose is a ketose belonging to the group of monosaccharides and has sweetness equivalent to sucrose [13]. It is well dissolved in water (Table 1) and does not undergo fermentation initiated by yeasts [14]. L-Sorbose, dissolved in water at $27^{\circ} \mathrm{C}$, appears in isomeric form as alpha-sorbopyranose.

\section{Materials and methods}

L-Sorbose in crystalline form was obtained from rowan berries cut to small pieces while sugar was extracted with demineralized water and ethanol used as the solvents. The clear solution was carefully decanted and subsequently poured into the flat opened dishes and kept for several weeks at room temperature in open air, undergoing slow evaporation to reach the state of slow crystallization. The obtained crystallites were separated from saturated solution, dried and crushed in the agate mortar. The identity of the obtained crystal powder was confirmed by refraction control with Rudolf J357 refractometer. The refraction coefficient measured was identical with that found for L-sorbose in the literature [15]. See also Table 1.

L-Sorbose crystals were irradiated in Co-60 source (Gamma Chamber 5000, dose rate $3.262 \mathrm{kGy} / \mathrm{h}$ ) with the dose of $4 \mathrm{kGy}$. The EPR examination has been done in X-band with Bruker ESP 300 spectrometer. The crystalline powder samples of L-sorbose (ca. $100 \mathrm{mg}$ each) was poured to EPR signal-free Wilmad ampoules $4 \mathrm{~mm}$ in diameter. One part of the samples was kept at room temperature. The other one was heated at $140^{\circ} \mathrm{C}$ in oil bath by 50 minutes. Heating temperature is close to L-sorbose melting point $\left(149^{\circ} \mathrm{C}\right.$ up to $158^{\circ} \mathrm{C}$ as reported for L-pyranose form of L-sorbose [15]). Heating for $50 \mathrm{~min}$ is optimal time to stimulate significant changes of EPR signal.

The EPR signals recorded with unheated and heated samples were normalized to the same intensity (integrated signal areas) and subtracted to obtain the differential spectrum. Discrete Fourier transform (DFT) simulation and relevant quantum-mechanical calculation and fittings were performed based on the Gaussian program 03W (demonstration version) to get the probable molecular structures of radicals involved.

\section{Results and discussion}

The normalized EPR signals of L-sorbose kept at room temperature and heated at $140^{\circ} \mathrm{C}$ (the temperature close to L-sorbose melting point) are shown in Fig. 2. As can be seen, both spectra differ significantly. It is in our opinion the consequence of the decay of less stable radicals at $140^{\circ} \mathrm{C}$. The remaining spectrum represents radicals, which do survive under such condition. The heating of L-sorbose crystals leads to specific selection of radicals produced in this sugar by radiation simplifying at the same time

Table 1. Characteristics of crystalline L-sorbose separated from rowan berries

\section{Crystallographic characteristics}

Solvent used for room temperature crystallization

Refraction coefficient $n$ of separated crystallites, $20^{\circ} \mathrm{C}$

Refraction coefficient $n$ of crystalline sorbose, literature data [15]

Solubility [g/100 g] in $17^{\circ} \mathrm{C}$ [16]
Orthorhombic needles ca. $0.05 \times 0.05 \times 0.9 \mathrm{~mm}$

$\begin{array}{cc}\begin{array}{c}\text { Distilled and demineralized } \\ \text { water }\end{array} & \begin{array}{c}\text { Ethanol of chemical } \\ \text { purity }\end{array} \\ 1.35458 \pm 0.00136 & 1.35795 \pm 0.00061 \\ 1.35484 \pm 0.00001 & 1.35484 \pm 0.00001 \\ \text { Highly soluble (83) } & \text { Less soluble (21) }\end{array}$




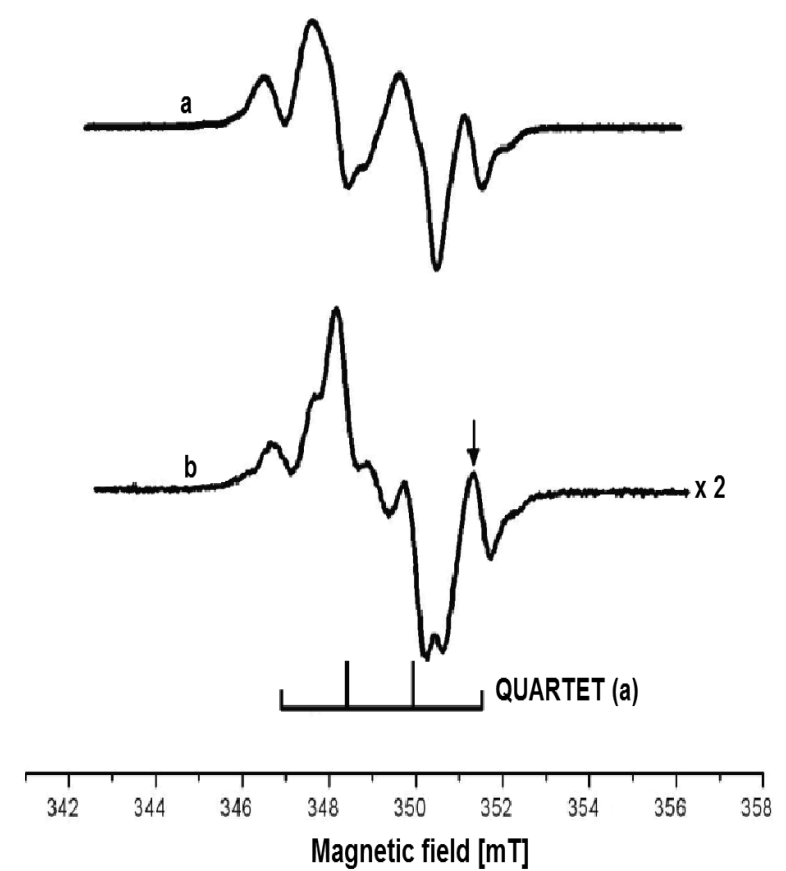

Fig. 2. EPR spectra of crystalline L-sorbose powder separated from rowan berries and $\gamma$-irradiated with the dose of $4 \mathrm{kGy}$ [10]. The upper spectrum (a) denotes unheated while lower one (b) heated $\left(140^{\circ} \mathrm{C}\right)$ sample. The scheme at the bottom indicates positions of the EPR lines of a quartet. The spectra are normalized vs. signal intensity. The reference line is marked with the arrow.

the EPR spectra recorded. Unexpected and different, as in the case of irradiated fructose or glucose [8-10], the signal recorded with unheated sample of L-sorbose is relatively simple with four dominating broad lines. However, the broadness of these lines, their partial asymmetry and appearance of shoulders suggest that each of four lines represents unresolved envelope of several undefined lines. The distance between the lines was found different confirming the above assumption.

The EPR signal of L-sorbose heated at $140^{\circ} \mathrm{C}$ during $50 \mathrm{~min}$ is different than that discussed above and is characterized by four sharp lines, which were not seen in the latter. A very similar distance between all four lines and specific proportion between their amplitudes (two central lines ca. three times higher than two outer ones) allowed us to assign this pattern to isotropic quartet with coupling constant $\Delta A=1.8 \pm 0.2 \mathrm{mT}$ (Fig. 2). The EPR differential signal obtained by computer subtraction of normalized spectra recorded with unheated and heated (at $140^{\circ} \mathrm{C}$ ) L-sorbose samples is highly anisotropic. Nevertheless, it is possible to distinguish two relatively strong lines in this signal, assigned by us to the isotropic doublet with coupling constant $\Delta A=2.3 \pm 0.2 \mathrm{mT}$ (Fig. 3)

Having identified isotropic quartet and isotropic doublet in the EPR signals recorded with unheated and heated radiation-treated samples of L-sorbose by spectral analysis, presumably derived from two dominant radicals giving rise to the complex EPR signal of this sugar, we undertook the effort to assign the defined radical structures to the EPR spectra. It has been done by applying the DFT simulation, making

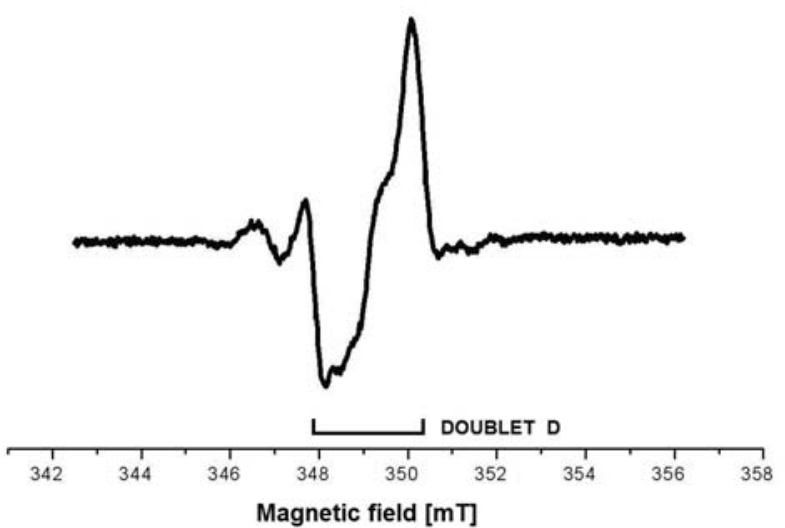

Fig. 3. The differential EPR spectrum obtained by subtraction of experimental EPR signal of L-sorbose heated at $140^{\circ} \mathrm{C}$ and of unheated one [10]. The scheme at the bottom denotes the position of doublet lines.

possible to indicate by fitting the probable molecular structures of radicals, giving rise to identified EPR spectra. The DFT simulation for the identification of molecular structures of radicals in irradiated sugars and their derivatives has been successfully applied earlier $[11,17,18]$. The goal of our study is the identification on the experimental basis of stable, isotropic spectra derived likely from two dominant radicals in crystalline sugar from the component of irradiated fruits, which have not been identified in the earlier studies. The most probable radical structures evoked by proton detachment from carbon atoms of pyranose ring were only considered. The DFT simulation processed with Gaussian program $03 \mathrm{~W}$ offered for isotropic quartet, with experimentally estimated coupling constant $\Delta A=1.8 \mathrm{mT}$, the radical molecule structure with unpaired electron at $\mathrm{C}-2$ carbon of the basic pyranose ring of L-sorbose interacting with three nuclear spins of hydrogen atoms bonded with $\mathrm{C}-1 \mathrm{a}(1.6 \mathrm{mT}), \mathrm{C}-1 \mathrm{~b}(1.5 \mathrm{mT})$ and C-3 $(1.4 \mathrm{mT})$ carbon atoms, respectively. The simulation processed for the identification of molecular structure of radical giving rise in EPR to isotropic doublet with experimentally estimated coupling constant $\Delta A=2.3 \mathrm{mT}$ delivers the best approximation the radical structure with unpaired electron at C-6a carbon atom of hydroxymethyl group outside pyranose ring of L-sorbose molecule interacting with hydrogen atoms bonded with $\mathrm{C}-6 \mathrm{~b}$ $(2.4 \mathrm{mT})$. The fittings done with the localization of unpaired electron at the remaining carbon atoms of L-sorbose molecule, which could eventually give rise to EPR quartet or doublet, did not deliver a comparatively good approximation. The proposed molecular structures of two dominant L-sorbose radicals offered by DFT simulation are shown in Fig. 4.

\section{Conclusions}

The identification by EPR of the isotropic quartet and isotropic doublet as dominant components of the complex EPR signal of crystalline L-sorbose extracted from rowan berries treated with ionizing radiation supported by DFT simulation based on experimentally estimated coupling constants allowed 

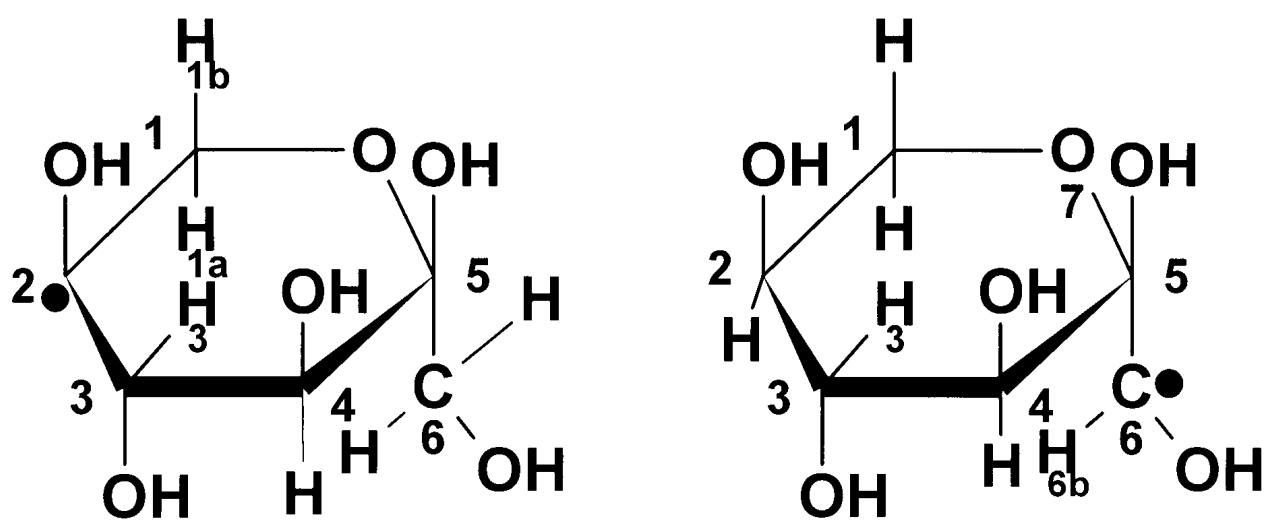

Fig. 4. The proposed structures of radicals stabilized in $\gamma$-irradiated L-sorbose obtained from the DFT simulation by the fitting based on the EPR spectra identified experimentally. Left scheme: radical giving rise to isotropic doublet in EPR. Right scheme: radical giving rise to isotropic quartet in EPR.

us to conclude that probably two radicals produced by hydrogen detachment from C- 6 and from C-2 carbon atoms of L-sorbose molecule are involved. The radical with unpaired electron at C- 6 carbon atom of the hydroxymethyl group outside the basic pyranose ring of L-sorbose molecule gives rise in EPR to an isotropic quartet, which is more stable at the temperature of $140^{\circ} \mathrm{C}$, then the other one with unpaired electron at C-2 link of the pyranose ring. It is expected, therefore, that by prolonged storage at ambient temperatures of radiation-treated dried fruits or nutritious articles containing crystalline L-sorbose slow transformation of the initially recorded EPR signal will appear. Such an effect has been found in our earlier EPR study on stable radicals in irradiated fructose after one year of observation [8]. The derived molecular structure of both the identified radiation-induced radicals resembles that of L-sorbose parent molecule supporting the view [11] that both radicals are the preliminary products of the radiation chemical process.

The localization of radiation-induced radicals in the crystalline, rigid lattice of L-sorbose guarantees their stability and resistance against the action of air oxygen, which is always present in fruits but does not diffuse inside the rigid lattice of crystals. The formation of identified radicals inside L-sorbose crystals only minimize the probability of intramolecular reactions of these radicals with the surrounding. However, due to relatively 'elastic' structure of organic crystals the probability of some radical-radical and radical-molecule interaction between trapped radical and the neighbouring parent molecule is increased, resulting in the observed slow radical decay. The intracrystal reactions could be one of the sources of dimers, the final products of the radiolysis identified with relatively high yields in irradiated sugars [19]. It is postulated that radiation chemical process in monosaccharides proceeds in several pathways of radical reactions, leading finally to the formation of the variety of stable molecular products of the structure differing from that of parent molecule and considered as the secondary products of radiolysis [19]. Stable radicals identified in our present and the earlier studies [8-10] represent molecular structure analogous to that of parent monosaccharide molecule as produced in the primary process of the detachment of hydrogen atom from the latter only. A similar conclusion has been drawn in our work on irradiated D-glucose [9] and is consistent with the opinion of other authors presented in their MLCFA (maximum likelihood common factor analysis) study on X-ray irradiated L-sorbose monocrystals [11].

The DFT simulation offers theoretically acceptable radical structures, which could be related to the isotropic EPR spectra identified experimentally, and are the spectral constituents of multiline signals observed in dried fruits exposed to radiation. Typically one or two structures are proposed, which could be adjusted to each of the identified spectra. However, DFT simulation does not deliver important information about the probability of the appearance of definite radical structure in real condition. For that reason, the proposed DFT assignments can be treated as a presumption only but fitting pretty well to experimental data.

Acknowledgment. The authors are grateful to Professor Jacek Michalik for his kind patronage of this work.

\section{References}

1. FAO/WHO. (1984). Codex general standard for irradiated foods and recommended international code of practice for the operation of radiation facilities used for the treatment of foods. In Codex Alimentarius (Vol. XV). Rome: Codex Alimentarius Commission.

2. Raffi, J., Agnel, J. -P., Buscarlet, L. A., \& Martin, C. C. (1988). Electron spin resonance identification of irradiated strawberries. J. Chem. Soc.-Faraday Trans. 1, 84, 3359-3362.

3. Raffi, J., Stachowicz, W., Migdał, W., Barabassy, S., Kalman, B., Yordanov, N., Andrade, E., Prost, M., \& Callens, F. (1998). Establishment of an eastern network of laboratories for identification of irradiated foodstuffs. Final Report of Copernicus Concerned Action. CCE. (CIPA-CT94-0134).

4. Raffi, J., Stevenson, M. H., Kent, M., Thiery, J. M., \& Belliardo, J. -J. (1992). European intercomparison on electron spin resonance identification of irradiated foodstuffs. Int. J. Food Sci. Tech., 27, 111-124.

5. Linke, B., Ammon, J., Ballin, U., Brockmann, R., Brunner, J., Delincee, H., Eisen, S., Eming, D., 
Eschelbach, H., Estendorfer-Rinner, S., Fienitz, B., Frohmut, G., Helle, N., Holstein, K., Jonas, K., Krolls, W., Kuhn, T., Kruspe, W., Marchioni, E., Meier, W., Pford, J., Schleich, C., Stewart, E., Trapp, C., Vreden, N., Wiezorek, C., Bogl, K. W., \& Schreiber, G. A. (1996). Elektronenspinresonanzspektro-skopische Untersuchungen zur Identifizierungbestrahlter getrockneter und trischer Fruchte: Durchführung eines Ringversuches an getrockneten Feigen und Mangos sowie an frischen Erdbeeren. Berlin: Bundesinstitut für gesundheitlichen Verbrau-cherschutz und Veterinärmedizin. (BgW-Hette 03/1996).

6. European Standard EN 1788:2002: Foodstuffs - Thermoluminescence detection of irradiated food from which silicate minerals can be isolated. Brussels: European Committee for Standardisation (CEN).

7. European Standard EN 13708:2003: Foodstuffs - detection of irradiated food containing crystalline sugar by ESR spectroscopy. Brussels: European Committee for Standardisation (CEN).

8. Guzik, G. P., Stachowicz, W., \& Michalik, J. (2008). Study on stable radicals produced by ionising radiation in dried fruits and related sugars by electron paramagnetic resonance spectrometry and photostimulated luminescence method. I. D-fructose. Nukleonika, 53(Suppl. 2), S89-S94.

9. Guzik, G. P., \& Stachowicz, W. (2013). Study on radicals giving rise to multicomponent EMR spectra in dried fruits exposed to ionizing radiation II. D (+) Glucose. Nukleonika, 58(3), 425-428.

10. Guzik, G. P., Stachowicz, W., \& Michalik, J. (2010). Study on organic radicals giving rise to multicomponent EMR spectra in dried fruits exposed to ionizing radiation. Curr. Top. Biophys., 33 (Suppl. A), 81-85.

11. Vanhaelewyn, G., Jansen, B., Callens, F. J., \& Sagstuen, E. (2004). ENDOR - assisted study of the stable
EPR spectrum of X-irradiated $\alpha$-L-sorbose single crystals: MLCFA and simulation decomposition analyses. Radiat. Res., 162, 96-104.

12. Kączkowski, J. (1993). Biochemia roślin (Vol. 2). Warszawa: Wydawnictwo Naukowe PWN.

13. Glaser, D. (2002). Specialization and phyletic trends of sweetness reception in animals. Pure Appl. Chem., 74(7), 1153-1158.

14. Collins, P. M. (Ed.). (2005). Dictionary of carbohydrates (p. 1282). Boca Raton: Chapman\&Hall/CRC.

15. International Commission for Uniform Methods of Sugar Analysis. (1998). Refractometry and Tables - Official (pp. 9-10). ICUMSA Publications Department c/o British Sugar Technical Centre. Norwich Research Park, Colney, Norwich no 47 UB, England.

16. Gajewska, I., Pietras, S., Rudzińska, J., \& Schellenberg, A. (Eds). (1974). Poradnik fizykochemiczny (2nd ed.) (part D, p. 276). Warszawa: Wydawnictwa Naukowo-Techniczne WNT.

17. Vanhaelewyn, G. C. A. M., Jansen, B., Pauwels, E., Sagstuen, E., Waroquier, M., \& Callens, F. J. (2004). Experimental and theoretical electron magnetic resonance study on radiation-induced radicals in L-sorbose single crystals. J. Phys. Chem. A, 108(16), 3308-3314. DOI: 10.1021/jp037886o.

18. Vanhaelewyn, G., Sadło, J., Callens, F., Mondelaers, W., Frenne, D., \& Matthys, P. (2000). A decomposition study of the EPR spectrum of irradiated sucrose. Appl. Radiat. Isot., 52(5), 1221-1227.

19. von Sonntag, C., \& Schuchmann, H. -P. (2001). Studies in physical and theoretical chemistry: Carbohydrates. In C. D. Jonah, \& B. S. M. Rao (Eds.), Radiation chemistry: Present status and future trends (pp. 481-509). Amsterdam: Elsevier. 